\title{
RASPAS E RESTOS DE FILOSOFIA NA BNCC -EM: trampolim para uma ética como experimentação
}

\author{
Ester Maria Dreher Heuser \\ Adriana Muniz Dias
}

\section{Resumo}

Partindo do arquivo de docência produzido no projeto Escrileituras: um modo de ler-escrever em meio à vida, o artigo apresenta uma perspectiva ética que se produz como experimentação. Considera o que restou da Filosofia na Base Nacional Comum Curricular, sobretudo de sua dimensão Ética. Como trampolim para criar tal perspectiva, utiliza uma constatação do documento sobre a indeterminação promovida, especialmente, pelas tecnologias digitais de informação e comunicação, a qual requer uma "nova mentalidade" e uma "ética diferente"; defende que as maneiras de levantar questões próprias à filosofia podem contribuir para uma postura cuidadosa e crítica; sustenta a função transcriadora e autoral da docência; explora a noção sociolinguística de "regras facultativas", que não opera por normatividade fixada nem erige códigos de conduta, para fazer emergir o que pode ser uma "ética diferente": que se constitui constantemente na experiência, operando processos de multiplicidade, avaliados conforme critérios que afirmam a vida.

Palavras-chave: BNCC; ética; experimentação; escrileituras

\section{SCRAPS AND REMNANTS OF PHILOSOPY IN THE NATIONAL COMMON CURRICULAR BASE:}

a trampoline for ethics as experimentation

\begin{abstract}
Based on the teaching file produced in the project Writreadings: a way of reading-writing in the midst of life, the article presents an ethical perspective that produces itself as experimentation. It considers what remains of Philosophy in the National Common Curricular Base, above all its Ethical dimension. As a trampoline to create such a perspective, it uses a statement of the document about the indeterminacy promoted, especially by digital technologies of information and communication, which requires a "new mentality" and a "different ethics"; it argues that ways of raising questions specific to philosophy can contribute to a careful and critical posture; it sustains the teaching's transcreation and authoring function; it explores the sociolinguistic notion of "optional rules", which does not operate by fixed norms nor erect codes of conduct in order to bring out what may be a "different ethics": which is constantly constituted in experience, operating processes of multiplicity, evaluated according to criteria that affirm life.
\end{abstract}

Keywords: BNCC; ethics; experimentation; writreadings

\section{SOBRAS Y RESTOS DE FILOSOFÍA EN EL BNCC -EM: un trampolín para la ética como experimentación}

Resumen

A partir del archivo de enseñanza producido en el proyecto Escrilecturas: un modo de leer-escribir en medio de la vida, el artículo presenta una perspectiva ética que se produce como experimentación. Considera lo que queda de Filosofía en la Base Nacional Común Curricular, sobre todo su dimensión ética. Como trampolín para crear tal perspectiva, utiliza una constatación del documento sobre la indeterminación promovida, especialmente, por las tecnologías digitales de la información y la comunicación, que requieren una "nueva mentalidad" y una "ética diferente"; defiende que las formas de plantear las cuestiones propias de la filosofía 
pueden contribuir a una postura cuidadosa y crítica; sostiene la función transcreadora y autoral de la enseñanza; explora la noción sociolingüística de "reglas facultativas", que no operan por normatividad fija ni erigen códigos de conducta para hacer emerger lo que puede ser una "ética diferente": que se constituye constantemente en experiencia, operando procesos de multiplicidad, evaluados según criterios que afirman la vida.

Palabras clave: BNCC; ética; experimentación; escrilecturas

\section{INTRODUÇÃO: RASPAS E RESTOS INTERESSAM}

Entre a primeira e a terceira versões da Base Nacional Comum Curricular do Ensino Médio (BNCC -EM, BRASIL, 2015; 2018), saltam aos olhos as perdas que as novas gerações sofreram do ponto de vista da formação cultural no que respeita às Ciências Humanas em geral. A dilapidação da Filosofia é flagrante. Como disciplina, matéria específica, ela desapareceu, junto com muitas outras. Dela, restam, ainda, alguns poucos traços mencionados de temáticas que lhe são próprias, mas não exclusivas, tais como política, estética, lógica, epistemologia e metafísica. Entre os restos, a Ética, que requer, necessariamente, uma abordagem filosófica, aparece com recorrência na BNCC -EM. Raspas e restos filosóficos interessam. Ao que sobrou das temáticas de Ética nos dedicamos neste artigo, com base, sobretudo, em nosso arquivo de docentes-pesquisadoras participantes do projeto de ensino, pesquisa e extensão Escrileituras: ler-escrever em meio à vida (OBEDUC/CAPES, 2011-2015) e da rede de pesquisa Escrileituras da diferença em filosofia-educação (CNPq). Nele, afirmamos a responsabilidade ética de nossa profissão, na medida em que não renunciamos à função transcriadora da docência e da aula como espaço-tempo de experimentações, também, éticas, a partir de escrileituras promotoras de processos de subjetivação capazes de contribuir para a invenção da vida.

\section{A BNCC COMO UM TRAMPOLIM}

Como resultado das lutas, bandeiras e atuação micropolítica de educadores que vieram antes de nós, tivemos, por quase uma década, a presença oficial da Filosofia nos currículos escolares do ensino médio e a criação de uma cultura de integração entre universidades e escolas, por meio de políticas de Estado como o PIBID e o Observatório da Educação. A macropolítica planificadora da Educação Nacional, a partir de 2016, após mudanças significativas na política nacional, contudo, alterou, por força de lei $(13.415 / 2017)$, as perspectivas relativas ao ensino médio, assim como as políticas curriculares nacionais, com a instituição de uma Base Nacional Comum Curricular $B N C C$. A lei prevê o aumento de carga horária anual do ensino médio, de oitocentas para mil horas, e a flexibilização curricular com os "itinerários formativos" e, ainda, a obrigatoriedade do ensino da matemática e das línguas portuguesa e inglesa nos três anos ${ }^{1}$. Não sabemos, ainda, exatamente, como isso funcionará, pois, apesar de as mudanças terem sido marcadas para começarem após a aprovação da BNCC, que se deu em dezembro de 2018, no Paraná, o estado em que trabalhamos, ainda não há Diretrizes para o ensino médio e, talvez devido à pandemia e à consequente educação on-line, os professores das escolas não estão se reunindo para se ocuparem coletivamente do funcionamento do "novo ensino médio".

Ocorre, entretanto, que a educação não é feita de uma só linha em que, em uma ponta estaria o Estado com seus poderes e, na outra, a escola com estudantes e professores, formatados de acordo com aquilo que "vem de cima". Não, a educação é um "fantástico tear". Tear feito de

1 Um resumo da lei e de seu funcionamento pode ser encontrado no Portal do MEC <http://portal.mec.gov.br/component/content/article?id=40361 > . Acesso em 21 jul. 2020. 
inúmeras linhas de macro e micropolíticas, de "sonhos da docência", sonhos daqueles que leem-eescrevem na e para a Aula (CORAZZA, 2020). Longe de nós aquilo que está na ponta da linha. Queremos saber do tear e de sua complexidade de linhas que se mostram no meio, pelo meio, em meio à vida. Concebemos a BNCC - com sua perspectiva hegemônica, a qual prioriza alguns campos de conhecimento mais do que outros, voltada para as avaliações nacionais e internacionais - apenas como uma das linhas desse tear.

Por não nos posicionarmos como consumidoras de um currículo feito por outros, por não delegarmos responsabilidades que são próprias da docência, por nos sentirmos triplamente responsáveis: 1) pela "[...] herança dos que nos antecederam, dos tempos que nos tocaram viver e trabalhar" (CORAZZA, 2016, p. 137); 2) pelos "novos" que nos chegam a cada ano; 3) por nossas aulas como espaços de invenção, inclusive em tempos de macropolíticas avessas a ela; concebemos a Base, na condição de um dos componentes do "fantástico tear" que é a educação, um "[...] trampolim para currículos que emerjam do dia-a-dia da docência, levando os professores a se tornarem, outra vez, os seus autores" (CORAZZA, 2016, p. 135). Como curriculistas e inventoras de didáticas, consideramos o documento e suas potencialidades, a fim de problematizar e mostrar, na extensão permitida deste artigo, possibilidades já experimentadas e estimular processos de singularização, que incluem o acaso e põem em jogo zonas de indeterminação entre filosofia e literatura capazes de lidar com uma ética como experimentação, sem fundamentação abstrata.

\section{A ÉTICA NA BNCC}

A ética é uma das dimensões a ser considerada para a "[...] formação e o desenvolvimento humano global" - ao lado das dimensões intelectual, física, afetiva, social, moral, simbólica - e incluída nos currículos a serem construídos a partir da BNCC (BRASIL, 2018, p. 16). Essas dimensões estão previstas para serem desenvolvidas ao longo da vida escolar, com vista a " [...] atender as necessidades de formação geral indispensáveis ao exercício da cidadania e responder à diversidade de expectativas dos jovens quanto à sua formação", tal como estabelecido pela Lei de Diretrizes e Bases. Conforme o Artigo 35, inciso terceiro, a formação ética está associada ao "[...] aprimoramento do educando como pessoa humana" (apud BRASIL, 2018, p. 464), capaz de "[...] construir e realizar seus projetos de vida, em consonância com os princípios da justiça, da ética e da cidadania" (BRASIL, 2018, p. 470).

Como se sabe, o discurso com aparência de nova concepção curricular é, em grande medida, o retorno às elaborações dos Parâmetros Curriculares Nacionais dos anos 90, com a educação orientada para o desenvolvimento de Competências (SILVA, 2018). Das "Competências gerais da Educação Básica”, destacamos três em que a Ética, seus temas e problemas mais diretamente relacionados aparecem: "[...] 5. Compreender, utilizar e criar tecnologias digitais de informação e comunicação de forma crítica, significativa, reflexiva e ética”; “[...] 6. fazer escolhas alinhadas ao exercício da cidadania e ao seu projeto de vida, com liberdade, autonomia, consciência crítica e responsabilidade"; "[...] 10. Agir [...] com autonomia, responsabilidade, flexibilidade, resiliência e determinação, tomando decisões com base em princípios éticos, democráticos, inclusivos, sustentáveis e solidários" (BRASIL, 2018, p. 9-10, grifos nossos). Dessas competências gerais, decorrem as específicas por áreas e suas habilidades. Temas filosóficos, sobretudo referentes ao elemento ético, são recorrentes mesmo em outras áreas que não as Humanas e Sociais Aplicadas.

Pode-se dizer que há duas grandes preocupações que atravessam o documento e requerem, primordialmente, uma formação ética dos estudantes, a saber: as tecnologias digitais de informação e comunicação (TDICs) e a sustentabilidade com consumo responsável. Sem dúvida, esses são problemas do nosso tempo que se impõem a todos. A filosofia não passa ao largo deles e, como o 
documento reconhece, ela tem muito a contribuir. Em nossa perspectiva, isso se dá mais pelo que ela pode proporcionar em seus modos de questionar e pensar do que pelo que já sistematizou em forma de teorias - no sentido kantiano, de que mais importa o filosofar do que a filosofia. Uma nota de rodapé do documento assume que as teorias éticas existentes não são suficientes para os novos problemas. Sobretudo os referentes a este mundo conectado em rede mundial. A BNCC reconhece que as TDICs, com a abundância de informações e produções, implicam "[...] novas práticas sociais e de linguagem" - visuais, sonoras, verbais e corporais -, por meio das quais, em ritmo de "pós-verdade", também correm notícias falsas e discursos de ódio. Nesse contexto de tematização é que o documento observa em nota: essas novas práticas "[...] operam a partir de uma nova mentalidade, regida por uma ética diferente (BRASIL, 2018, p. 478, n. 60, grifos nossos).

Apesar das certezas que proliferam ao longo das mais de 500 páginas do conjunto da Base para toda a educação básica; apesar de algumas definições de ética, inclusive desencontradas e que não cabem ser analisadas nesse artigo; apesar de, em sua Apresentação, o documento afirmar-se como um todo articulado e coerente, mas identificarmos muitas contradições; consideramos que essa nota de rodapé marca uma indeterminação interessante, ao menos para o trabalho com ética, tal como a concebemos. Não se sabe que nova mentalidade é essa, nem a ética que a rege, uma vez que, por ser qualificada como "diferente", sugere não se referir a nenhuma ética pertencente ao amplo repertório filosófico. Para tempos de incertezas e de indeterminação, essa nota pode funcionar como uma linha de fuga, um punhadinho de terra ao qual um professor poderá se apegar, nos sentidos deleuze-guattarianos, para a criação de/nas aulas. A indeterminação dessa nota é o nosso trampolim “[...] para saltarmos sobre os interesses hegemônicos", sobre as ideias feitas e correntes da própria Filosofia, e criarmos condições para "[...] curricularizar e didatizar, criadoramente", no século que nos coube viver, com suas condições e juventudes (CORAZZA, 2016, p. 141).

\section{UMA ÉTICA PARA EXPERIENCIAR O SÉCULO XXI: MANEIRISMO FILOSÓFICO}

Ao determinar o contexto do ensino médio na educação básica, a BNCC afirma que, para acolher a juventude, "[...] as escolas devem proporcionar experiencias e processos intencionais que lhes garantam as aprendizagens necessárias”, o que implica ultrapassar a pretensão de que os jovens estejam limitados a aprender o que sabemos e apresentar-lhes o mundo "[...] como campo aberto para investigação e intervenção quanto a seus aspectos sociais, produtivos, ambientais e culturais" (BRASIL, 2018, p. 463, grifos nossos). Concepção que nos parece condizente com o mundo como está, que ajudamos a produzir, aliás, relacionada também com o que, no mundo, se sonha, com um porvir que ainda não é.

Apresentar um duplo do mundo, aquilo que dele fizemos e já sabemos e como um "campo aberto" exige que operemos com uma "nova mentalidade", regida por uma ética que ainda não se sabe exatamente qual é, simplesmente diferente daquelas que temos, uma vez que o próprio mundo ultrapassou as mentalidades existentes e as éticas por elas constituídas. Portanto, as respostas éticas sobre nós, os outros e o mundo ficaram para trás, mas precisam nos acompanhar, na forma de textos e de seus efeitos no mundo, porque fazem parte do legado e podem ser matéria-prima para formular novos problemas e soluções, assim como para pensar nossa condição humana no XXI.

Consoante com o foco do que a escola deve proporcionar aos jovens, experiências e processos, em filosofia, que é um modo específico de experiências do pensamento, o qual, necessariamente, passa por processos - e talvez seja unicamente processo, uma vez que os conceitos não param de mudar (DELEUZE; GUATTARI, 1992) -, a maneira de levantar questões importa muito. Para nós, é 
decisiva. Por defendermos que o trabalho com a Filosofia precisa ser feito em diálogo com textos da herança filosófica, assim como em composição com a não filosofia, faz sentido tratá-los como expressões de experiências singulares de pensamento, produzidas em meio a dinamismos espaçotemporais. Estes são constituídos em função de uma tipologia (quem?), de uma topologia (onde?), de uma posologia (quando?), de uma casuística (em que caso?), que determinarão as condições em que seus pensamentos foram produzidos. Daí esses dinamismos serem chamados de transcendentais, por se ocuparem das condições de tal produção (DELEUZE, 2006). Se trata, pois, de ir além da resposta produzida pela questão que é? , de se dirigir para as condições de sua produção e tomar esse processo como modos de pensar, os quais podem funcionar também para nos ocuparmos dos problemas que se impõem ou daqueles que criamos.

Essa pode ser a maneira mais adequada de a Filosofia contribuir para aquilo que, à Base, é essencial para o desenvolvimento da "[...] autonomia dos sujeitos diante de suas tomadas de decisão na vida", a saber: “[...] aprender a indagar, ponto de partida para uma reflexão crítica”, uma vez que "[...] a pergunta bem elaborada e a dúvida sistemática contribuem igualmente para a construção e apreciação de juízos sobre a conduta humana, passível de diferentes qualificações” (BRASIL, 2018, p. 549). Fazemos uma aposta: se esse "maneirismo" filosófico for exercitado, ele poderá ser transformado em hábito do pensamento e tornar-se costume, o grande guia da vida humana (HUME, 2000). Uma pessoa que pensa indagando os dinamismos, as condições daquilo que se apresenta, jamais aceitará acriticamente “[...] como verdade o 'fato' veiculado nas diferentes mídias"; necessariamente ele se porá a "[...] desvendar e reconhecer os sujeitos, os sentidos obscuros e silenciados, as razões da construção de uma determinada informação e os meios utilizados para a sua difusão" (BRASIL, 2018, p. 548).

Internalizar o maneirismo filosófico de interrogar, que tem muitas nuances caracterizadoras dos modos próprios de os filósofos pensarem, pode ser a melhor estratégia para que os jovens saibam lidar com as tecnologias digitais e seus "[...] apelos consumistas e simbólicos capazes de alterar suas formas de leitura de mundo, práticas de convívio, comunicação, participação política e produção de conhecimento, interferindo efetivamente no conjunto das relações sociais" (BRASIL, 2018, p. 549). Ou seja, cultivar hábitos filosóficos pode tornar mais complexa e interessante a invenção de modos de vida que se dão em duas dimensões, as quais o documento, estranhamente ${ }^{2}$, distingue como "real" e "virtual", o que implica uma "ação ética" (BRASIL, 2018, p. 555). Esse cultivo associamos à ética como experimentação.

\section{ÉTICA COMO EXPERIMENTAÇÃO}

A noção de ética como experimentação foi, primeiro, vivida e experienciada durante o projeto de ensino, pesquisa e extensão Escrileituras: um modo de ler-escrever em meio à vida, realizado entre 2011 e 2015, interinstitucionalmente (UFRGS, UFPel, UNIOESTE e UFMT) e financiado pelo MEC/CAPES, via Observatório da Educação (CORAZZA et al., 2017).

Ao longo do processo de realização do projeto, aqueles que praticavam a docênciapesquisa, em múltiplos espaços educativos, agiam orientados pela ideia de tradução desenvolvida por Haroldo de Campos (2013), a qual ele nomeou de "transcriação". Ainda que não se tratasse de verter, criativamente, como Campos, o texto de uma língua estrangeira para a materna, assumimos a posição de transcriadores, na medida em que agimos como intérpretes criativos das matérias

2 Distinção há muito desfeita pela Filosofia (DELEUZE, 1998) e difundida por Pierre Lévy (https://www.youtube.com/watch?v=sMyok16YJ5U), mas ignorada pelo documento, apesar de mostrar preocupação com as TDICs. Acesso em 21 jul. 2020. 
originais advindas das artes, das ciências e da filosofia. Ou seja, afirmamos um papel autoral e não abrimos mão desse direito ao criarmos as nossas aulas, pois nele está implicada uma "[...] função interpretativa e valorativa dos problemas e conceitos" com os quais lidamos no trato com a filosofia.

Sustentamos que é graças a essa nossa função que a filosofia "[...] não se transforma em letra morta"; que somos nós quem damos "[...] prosseguimento ao vitalismo de ideias, argumentos e temas filosóficos" e, assim, garantimos "[...] sobrevida à História da Filosofia", na medida em que, em nossas pesquisas, planejamentos e aulas, renovamos "[...] os desdobramentos problemáticos próprios a esse modo de pensar" (HEUSER, 2018, p. 116). Com a demarcação de tal posição, o projeto afirmou a devida "[...] importância civilizatória e cultural, bem como as responsabilidades éticas por ela implicadas" da docência e do docente (CORAZZA et al., 2017, p. $31)^{3}$.

No caso da ética como experimentação e o trabalho dela com jovens, em escolas, universidades e outros meios formativos, as matérias originais com as quais lidamos para transcriar são oriundas da filosofia e da literatura ${ }^{4}$. Entre a Filosofia e a não filosofia, a escrita e a leitura criativas (escrileituras), inventamos modos produtivos de processos de subjetivação que colaboram na produção de si mesmo, rompendo com a fixação do Eu - tanto a dos estudantes quanto a dos professores. Isso possibilita a proliferação de modos de existir singulares, não padronizados, ainda que a singularização se passe em detalhes de uma vida que, aparentemente, siga padrões, por exemplo, aqueles que a BNCC chama de "culturas juvenis" (BRASIL, 2018, p. 461), o que implica problematizar como alguém aprende, pois a constituição de singularidades envolve um modo de aprender e, por isso, não se separa da educação.

$\mathrm{Na}$ literatura, encontramos uma prodigalidade quase infinita de casos de aprendizados $\mathrm{em}$ processo. Eles permitem abrirmos o problema de como alguém aprende para além do que a psicopedagogia e as teorias cognitivistas fazem. Marcel Proust, com sua série de romances Em busca do tempo perdido (2002), foi nosso caso literário de processo de subjetivação, associado ao livro de Deleuze (2010) Proust e os signos, lido por nós como uma obra de ética, na qual ele trata do aprendizado de um homem de letras, de sua constituição no encontro com signos que o ensinam, no sentido de lhe darem material para constituir sua existência singular.

A partir dessas matérias, produzimos menos uma definição e mais um modo de abordar a ética; de lidar filosoficamente com ela, em meio à vida. Por isso, a designamos "ética como experimentação". Propositalmente, não se pode afirmar que ela tenha um conceito fixado, definido, acabado, à espera de ser estudado e ensinado. Contrariamente, ela trata de um contínuo movimento e, por isso, não existe fora da experimentação. Constitui-se constantemente na própria vida, operando processos de multiplicidades.

Não deixamos de compor uma concepção ou ideia de ética, mas ela é movente, não se deixa capturar totalmente. Constitui uma superfície de inscrição, no sentido de que se aproxima daquele que Valéry expressou na frase "[...] o mais profundo é a pele” (cf. DELEUZE, 2013, p. 113). Pois, como explica Maria Idalina Krause de Campos (2018), não há, para Valéry, ideia fixa, mas pensamentos que buscam acontecer entre corpo-espírito-mundo, sobretudo aqueles que causam grande tormento, sendo a pele o tecido, a superfície potencial para que nossa sensibilidade capture acontecimentos traduzidos via palavra, cuja força de expressão se afirma em uma escrita encarnada potencialmente.

\footnotetext{
3 Além de artigos publicados em revistas, as produções do projeto foram publicadas em uma coleção intitulada Escrileituras, disponível em https://www.ufrgs.br/escrileiturasrede/colecao-escrileituras/. Acesso em 17 jul. 2020.

4 Este trabalho de Pesquisa e Ensino, que compõe nosso arquivo de docência, está disponível em http://tede.unioeste.br/handle/tede/3129. Acesso em 10 nov. 2020.
} 
Em favor da experimentação, essa perspectiva ética difere de uma verdade estabelecida historicamente que, necessariamente, foi produzida a partir de experimentações, as quais, todavia, foram deixadas de lado, esquecidas, no gesto de sua teorização. Em suma, uma ética como essa não ignora a experimentação, não esquece que é pensamento em movimento. Como dizem Deleuze e Guattari (1992, p. 143), em O que é Filosofia?: "[...] pensar é experimentar, mas a experimentação é sempre o que se está fazendo - o novo, o notável, o interessante, que substituem a aparência de verdade e que são mais exigentes que ela. O que se está fazendo não é o que acaba, mas menos ainda o que começa”. Daí o sentido de nos ocuparmos de processos do pensar e do aprender.

Esse modo de relacionar o pensamento à experimentação difere das maneiras com que, comumente, a filosofia é concebida e recebida. Opõe-se à ideia de interpretação de algo que está à espera de ser apropriado e ressignificado. Preocupa-se mais com o funcionamento do que com o significado das ideias. Na ética como experimentação, ao invés de perguntar-se "o que isso quer dizer?", indaga-se: "como isso funciona?"; "isso funciona para você?"; "como funciona na composição com as outras peças da sua vida?". Ela se permite assim agir porque está orientada por "regras facultativas" que não determinam obrigatoriedades, não operam por normatividade fixada nem erigem códigos de conduta e muito menos fundamentos universalmente válidos.

A noção de regras facultativas provém da sociolinguística de William Labov, que investigou os usos das línguas em situações contemporâneas concretas, fazendo análise sistemática da fala em seu contexto social. Construiu um instrumento de descrição, que chamou de "regras facultativas", sem excluir qualquer variação social, os dialetos, por exemplo, do campo da linguística. Ou seja, analisou as línguas em seus usos, em meio à vida, considerando-as instrumentos de comunicação em uma comunidade de fala e não como um "sistema monolítico, uniforme e homogêneo" (FONSECA, 2007, p. 20). Essa noção é referida por Deleuze, em Foucault (2005, p. 108 [nota de rodapé 18]), para problematizar o "estatuto do enunciado", para designar "[...] funções de variação interna e não mais constantes"; por fim, em um sentido mais geral, para designar "[...] funções reguladoras que se distinguem dos códigos".

Ao lidar com essas regras, Deleuze amplia seu uso para além dos códigos linguísticos. Nos mostra que elas funcionam como uma variação nos códigos que regulam o agir das pessoas e as relaciona ao processo de constituição da subjetividade que se insurge à identidade fixa, a normas de conduta homogênea. Em suas palavras: "[...] a luta pela subjetividade se apresenta, então, como direito à diferença e direito à variação, à metamorfose" (DELEUZE, 2005, p. 118). Deste modo, o conceito de regras facultativas adquire, com Deleuze, "[...] a definição de funções reguladoras diferentes dos códigos, não somente dos códigos linguísticos, científicos, mas também dos códigos morais, que efetuam, assim como os outros tipos de códigos de saber, relações de poder e as regras obrigatórias que lhes são características" (BARBOSA, 2015, p. 56).

A aproximação da ética como experimentação à perspectiva de Labov é ainda mais estreita. Ele considerava ser temeroso prescindir da dimensão social da língua, uma vez que, sem ela, a análise linguística se limita a explicações internas. Por essa razão, deixa sem solução adequada diversas questões acerca do sistema linguístico, que é vivo, porque é o meio no qual as pessoas vivem com outros, convivem. Por sua vez, a ética como experimentação considera as relações das pessoas consigo mesmas, com os outros, com o meio e o tempo em que vivem, suas condições culturais, sociais, econômicas e o mundo. O que fez Labov e o que propomos nós é dizer sim à variação e à diferença como constituintes da vida. É admitir o óbvio que a espécie humana tende a negar e até a expiar (CAMACHO, 2010); é avaliar positivamente os efeitos da diferença para a riqueza da vida. Trazemos a variação e a mudança para o centro das experimentações éticas. $\mathrm{O}$ mesmo que Labov afirmou acerca da heterogeneidade, das variações sociais, culturais e estilísticas 
como constituidoras do comportamento expressivo do falante e responsáveis por possibilitarem a imensa multiplicidade de maneiras de dizer algo, as quais, do ponto de vista do seu valor referencial ou de verdade se equivalem, mas se diferenciam em termos de significação social e expressiva, afirmamos para a ética como experimentação. Em suma, sustentamos que os acontecimentos reais, até os "insignificantes", como tantos narrados na literatura - virtuais e atuais -, aquilo que se passa nas vidas é o que constitui a matéria principal da ética como experimentação, em meio a essas vidas, tendo elas em perspectiva é que trabalhamos com textos filosóficos de Ética.

Não se trata, contudo, de cair em um relativismo absoluto. As regras facultativas, mesmo variáveis, não tendo intenções universalistas nem princípios fundantes, permitem que a ética como experimentação determine critérios orientadores da ação. Elas “[...] desmontam a falsa alternativa entre as regras coercitivas (a moral), por um lado, e a ausência total de regras ou a equiparação dos valores (o niilismo), por outro lado, e fornecem critérios para a avaliação durante a experimentação" (BARBOSA, 2015, p. 71). Nelas se encontram elementos que tornam possível buscar seus referenciais nas experimentações, na afirmação da vida, pois:

[...] não temos a menor razão para pensar que os modos de existência tenham necessidade de valores transcendentes que os comparariam, os selecionariam e decidiriam que um é "melhor" que o outro. Ao contrário, não há critérios senão imanentes, e uma possibilidade de vida se avalia nela mesma, pelos movimentos que ela traça e pelas intensidades que ela cria, sobre um plano de imanência; é rejeitado o que não traça nem cria. Um modo de existência é bom ou mau, nobre ou vulgar, cheio ou vazio, independente do Bem e do Mal, e de todo valor transcendente: não há nunca outro critério senão o teor da existência, a intensificação da vida (DELEUZE; GUATTARI, 1992, p. 98).

Ou seja, a própria vida é o critério da ética como experimentação. É nos encontros em que os corpos e os pensamentos se compõem e se decompõem, no sentido spinozista e proustiano, que as regras variáveis permitem avaliar quando um encontro afirma a vida ou a decompõe. Somente a partir das vivências, das experimentações, inclusive com textos, é possível avaliar o que é melhor para compor afirmativamente um modo de existência. O único critério possível para escolher e optar por uma maneira de viver e não outras é a própria vida (HEUSER, 2019).

Com a devida responsabilidade ética frente à herança filosófica que recebemos, transcriamos; tornamos vívidos textos de filosofia e de literatura para legá-los aos estudantes. A fim de trabalhar com os materiais dessa herança, por meio da ética como experimentação que se coloca em combate contra o que diminui a potência de viver, os tratamos no sentido deleuzeguattariano de que os livros de filosofia e a arte em geral "[...] têm em comum resistir, resistir à morte, à servidão, ao intolerável, à vergonha, ao presente" (DELEUZE; GUATTARI, 1992, p. 142). Encontrar-se com um texto vivificado, composto de dinamismos espaço-temporais, concebido como efeito de um processo que expressa pensamentos, compostos de problemas e conceitos, no caso de um texto filosófico, de seres de sensação, no caso da literatura, que resistem a algo intolerável, e, frente a ele, dramatizar, por meio daquilo que chamamos maneirismo filosófico, é dar a todo o ensino de filosofia um caráter ético. Implica responsabilidade com a herança e com os jovens que a recebem como obra aberta.

As experimentações que realizamos durante o projeto Escrileituras, e que agora compõem nosso arquivo de docência, exigiram que os encontros com os textos fossem também encontros com algo da vida de cada um; afinal, os textos só podem fazer sentido se, ainda que minimamente, tiverem ponto de contato com algo que compõe a vida do leitor, que se tornará escrileitor. Avaliamos que um texto de ética só funciona se operar como uma espécie de lente para pensar a si mesmo, ainda que ele seja a antítese do estado em que se encontra o si, como costuma acontecer 
nas aulas com textos de Nietzsche, em que critica o cristianismo e as noções de Bem e Mal, por exemplo, causando grande abalo e temor nos estudantes pensar a vida sem Deus e os sentidos da expressão "Deus está morto". Ideias contidas nos textos filosóficos poderão ou não compor com o modo de vida que se deseja produzir, o qual, na vida escolar, passa pela experiência de escrita, que pode servir para causar efeitos em quem escreve e em quem lê. Sobretudo se forem efeitos que abalem os modos acostumados de pensar, se operarem como forças externas à harmonia das faculdades dos estudantes (HEUSER, 2010).

Proust é um caso emblemático para nós: de um lado, sua escrita causou efeitos que direcionaram o modo de existência próprio, fazendo-o desejar viver a vida que inventou para si, mesmo em meio à decadente vida burguesa francesa; de outro, pode ou não funcionar como provocador de desejos de existência em quem o lêt $\hat{e}^{5}$ Ensinar também funciona assim. As elaborações conceituais da tradição apresentadas aos estudantes podem permanecer inertes ou funcionarem como máquinas que forçam as faculdades e animam o desejo de aprender, problematizar e buscar respostas para os problemas. Esses três movimentos - despertar das faculdades, desejar e buscar respostas — implicam a ética como experimentação. Quando a filosofia, a literatura, a escrita e a leitura funcionam como máquinas que produzem processos de subjetivação, elas tratam de criar modos de existência que podem ser afirmativos ou não. Ao professor cabe o papel de ser um emissor de signos variados, "[...] um ensignador que, a cada aula, experimente estabelecer oportunidades para que o começo do pensar no pensamento [como criação e não recognição], o seu nascimento, aconteça, ainda que as experiências fracassadas sejam em maior número" (HEUSER, 2011, p. 64).

\section{CONSIDERAÇÕES FINAIS: FILOSOFIA PARA O CIDADÃO SAIR DO PAPEL}

Enfim, o Brasil tem uma Base Comum Curricular. É provável que ela não seja $A$ Base dos sonhos de ninguém, dadas as negociações e acordos feitos com "[...] diferentes atores do campo educacional e com a sociedade brasileira" (BRASIL, 2018, p. 5). Mas temos a versão que as forças políticas, sociais, econômicas e educacionais foram capazes de compor, com todos os seus antagonismos e incoerências. É esse o documento que orienta, ao menos no presente e futuro próximo, os municípios, os estados e as escolas a criarem suas diretrizes curriculares e seus currículos. É com base também nela, mas ainda com seus sonhos, desejos, em razão da composição de suas turmas, das condições com as quais trabalham, que os professores inventarão suas aulas.

A Filosofia, juntamente com a Área das Ciências Humanas e Sociais Aplicadas, foi subtraída. Há raspas e restos, sobretudo no campo da Ética, que tem centralidade no conjunto do documento. Isso porque, sem filosofia, não há projeto de educação de qualquer tipo. Por mais servil ao Capitalismo e ao Mercado, por maior que seja o caráter instrumental e de adaptação ao status quo de um projeto de educação, ele sempre precisará de uma filosofia. A Filosofia, como uma das criações do pensamento, sempre operará multiplamente. Por sua natureza, ela sempre será plural e funcionará em variação contínua.

É próprio da Educação e da Filosofia criarem saídas imprevistas pelas estratificações do sistema. Sempre será possível atuar com o indeterminado, com o impensado. Ainda que nos

\footnotetext{
5 Vivemos experiências muito marcantes com uma composição criada a partir da obra Em busca do tempo perdido (PROUST, 2002 - o tomo À sombra das moças em flor), realizadas em vários lugares, com diferentes faixas etárias. Essa composição resultou na Oficina de Escrileituras “Desconstruir o texto, viajar por suas múltiplas janelas". Essa oficina aproximou a filosofia com a literatura, por meio de uma leitura dramática de fragmentos do romance, que conta a primeira viagem de trem de Marcel em direção a Balbec. Foi desenvolvida para ser realizada dentro de um ônibus em movimento, com cerca de trinta e cinco participantes (DIAS; BRACHT, 2015).
} 
interstícios das grades curriculares, será possível trabalhar na lógica da experimentação. Um professor transcriador constantemente poderá compor-se com as forças que atuam em favor das escolhas filosóficas que faz, poderá sonhar a docência e tornar suas aulas instantes para pôr o pensar em curso. Um professor, por mais restritas que sejam as condições, sempre poderá fazer da aula uma experiência, usar-se da ética como experimentação para tornar a herança um "[...] saber que forma e transforma a vida [...] em sua singularidade [que] produz diferença, heterogeneidade e pluralidade" (LARROSA, 2002, p. 28).

Está mais do que evidente na Base que, sem Filosofia, o Estado brasileiro não realizará a promessa às novas gerações. O cidadão tão almejado não deixará de ser de papel. Independente do itinerário formativo que o jovem escolher, a ética como experimentação é uma linha do fantástico tear da Educação que pode ajudá-lo a compor a criação de uma maneira de vida pessoal e coletiva, que vive e deixa viver afirmativamente.

\section{REFERÊNCIAS}

BARBOSA, Mariana de Toledo. Regras facultativas ou variáveis: a regulação da vida na ética deleuziana. Revista Trágica: estudos de filosofia da imanência, Rio de Janeiro, v. 8, n. 2, p. 54-722, 2. quadrimestre, $2015 . \quad$ Disponível em https://revistas.ufrj.br/index.php/tragica/article/view/26816/14906 . Acesso em 20 jul. 2020.

BRASIL, Ministério da Educação. Base Nacional Comum Curricular. Brasília: MEC, SEB, 2015. Disponível em http://basenacionalcomum.mec.gov.br/images/relatorios-analiticos/BNCC APRESENTACAO.pdf. Acesso em 20 jul. 2020.

BRASIL, Ministério da Educação. Base Nacional Comum Curricular. Brasília: MEC, SEB, 2018. Disponível em http://basenacionalcomum.mec.gov.br/images/BNCC EI EF 110518 versaofinal site.pdf. Acesso em 20 jul. 2020.

CAMACHO, Roberto Gomes. Uma reflexão crítica sobre a teoria sociolinguística. DELTA: Documentação de Estudos em Linguística Teórica e Aplicada. São Paulo, v. 26, n. 1, p. 141-162, 2010. Disponível em https://www.scielo.br/pdf/delta/v26n1/06.pdf. Acesso em 22 jul. 2020.

CAMPOS, Haroldo. Da tradução como criação e como crítica. In: TÁPIA, Marcelo; NÓBREGA, Telma Médici (org.) Haroldo de Campos - Transcriação. São Paulo: Perspectiva, 2013.

CAMPOS, Idalina Krause de. Paul V aléry educador. Porto Alegre: Ed. Mikelis, 2018.

CORAZZA, Sandra Mara et al. Entre a macro e a micropolítica, o Escrileituras: um modo de lerescrever em meio à vida. In: BACKES, José Licínio; PAVAN, Ruth (org.). A universidade vai à escola pública em tempos de avaliação em larga escala. Campinas: Mercado de Letras, 2017.

CORAZZA, Sandra Mara. O sonho da docência: fantástico tear. Revista Pro-posições (no prelo), 2020.

CORAZZA, Sandra Mara. Base Nacional Comum Curricular: apontamentos crítico-clínicos e um trampolim. Revista Educação, Porto Alegre, v. 39, n. esp. (supl.), p. 135-144, dez. 2016.

DELEUZE, Gilles. Conversações. Tradução: Peter Pál Pelbart. São Paulo: Ed. 34, 2013.

DELEUZE, Gilles. Foucault. Tradução: Claudia Sant'Anna Martins. São Paulo: Brasiliense, 2005.

DELEUZE, Gilles. O método de dramatização [1967]. Tradução: Luiz Orlandi. In: A ilha deserta e outros textos. Edição preparada por David Lapoujade. Organização da edição brasileira e revisão técnica: Luiz B. L. Orlandi. São Paulo: Iluminuras, 2006. p. 129-154.

DELEUZE, Gilles. Proust e os signos. Tradução: Antonio Piquet e Roberto Machado. Rio de Janeiro: Forense Universitária, 2010. 
DELEUZE, Gilles; GUATTTARI, Félix. O que é a filosofia? Tradução: Bento Prado Jr. e Alberto Alonso Muñoz. Rio de Janeiro: Ed. 34, 1992.

DELEUZE, Gilles; PARNET, Claire. Diálogos. Tradução: Eloisa Araújo Ribeiro. São Paulo: Escuta, 1998.

DIAS, Adiana Muniz. Uma ética da experimentaşão: Deleuze, Guattari e Proust no combate ao sistema de juízos. Dissertação (Mestrado em Filosofia) - Universidade Estadual do Oeste do Paraná UNIOESTE, Toledo, 169p. 2017. Disponível em http://tede.unioeste.br/handle/tede/3129. Acesso em 10 nov. 2020.

DIAS, Adriana Muniz; BRACHT, Shirlei. O processo de construção de uma oficina de transcriação: desconstruir o texto, viajar por suas múltiplas janelas. In: Seminário Educação 2014: Educação e seus modos de ler-escrever em meio à vida, 22., 2014, Cuiabá. Anais eletrônicos... Cuiabá: Universidade Federal de Mato Grosso. Instituto de Educação, 2014. p. 5882-5891. Disponível em http://sistemas.ufmt.br/ufmt.evento/Site.aspx?conteudoUID=182\&eventoUID=59. Acesso em 11 nov. 2020.

FONSECA, Simone Meckler. O problema das proparoxitonas: a perda da vogal postônica. 68f. Dissertação, Pós-Graduação em Letras, Universidade Federal de Juiz de Fora, Juiz de Fora, 2007. Disponível em https://www2.ufjf.br/ppglinguistica//files/2009/12/FONSECASimoneMeckler-2007-Disserta\%c3\%a7\%c3\%a3o.pdf. Acesso em 20 jul. 2020.

HEUSER, Ester Maria Dreher. Pensar em Deleuze: violência e empirismo no ensino de filosofia. Ijuí: UNIJUÍ, 2010.

HEUSER, Ester Maria Dreher. Estudos em torno da busca de um começo para pensar: do poderoso "Eu" ao impoder essencial do pensamento. In: MONTEIRO, Silas Borges (org.). Caderno de notas 2: rastros de Escrileituras. Canela: UFRGS, 2011, p. 45-65. Disponível em https://drive.google.com/file/d/1XoULx2wKI1p7-EW6FPsuU5sY-kCWThLx/view. Acesso em 10 nov. 2011.

HEUSER, Ester Maria Dreher. O que um professor transcria ao ensinar filosofia? In: RODRIGUES, Carla Gonçalves et al (org.). Caderno de notas 10: Traduções do arquivo Escrileituras. Porto Alegre: UFRGS, 2018, p. 107-124. Disponível em https://www.ufrgs.br/escrileiturasrede/colecao-escrileituras/. Acesso em 10 nov. 2020.

HEUSER, Ester Maria Dreher (org.). Contra o juízo: Deleuze e os herdeiros de Spinoza. Curitiba: Appris, 2019.

HUME, David. Tratado da natureza bumana. Tradução: Déborah Danowski. São Paulo: Unesp, 2000.

LARROSA, Jorge Bondía. Notas sobre a experiência e o saber de experiência. Revista Educação brasileira, Rio de Janeiro, n. 19, p. 20-28, jan./fev./mar./abr. 2002. Disponível em https://www.scielo.br/pdf/rbedu/n19/n19a02.pdf . Acesso em 20 jul. 2020.

PROUST, Marcel. Em busca do tempo perdido. Tradução: Fernando Py. v. 1, 2, 3. Rio de Janeiro: Ediouro, 2002.

SILVA, Monica Ribeiro da. A BNCC da reforma do ensino médio: o resgate de um empoeirado discurso. Educação em Revista, Belo Horizonte, v. 34, e214130, p. 1-15, 2018. Disponível em https://www.scielo.br/scielo.php?script=sci_abstract\&pid=S0102-

$46982018000100301 \& \operatorname{lng}=$ pt\&nrm=iso. Acesso em 21 jul. 2020. 


\section{Informações das autoras}

Ester Maria Dreher Heuser

UNIOESTE - Universidade Estadual do Oeste do Paraná, Campus Toledo

E-mail:esterheu@hotmail.com

ORCID: http://orcid.org/0000-0002-1762-7526

Link Lattes: http://lattes.cnpq.br/5548908138476554

Adriana Muniz Dias

SEED/PR - Secretaria Estadual de Educação do Paraná

E-mail: filoadri2008@hotmail.com

ORCID: http://orcid.org/0000-0002-1762-7526

Link Lattes: http://lattes.cnpq.br/3882358716647901 